\title{
PARENTS' VOICES: experiences and coping as a parent of a child with autism spectrum disorder
}

\author{
Gwen Reddy, BOT (UDW), MOT (UKZN) https://orcid.org/0000-0002-1966-2042 \\ Clinician at Peter Pan School and private practice \\ Deborah L Fewster, BOT (UDW), MPhil in Group therapy https://orcid.org/0000-0002-9424-8976 \\ Lecturer, Occupational Therapy Department, University of KwaZulu-Natal, Westville Campus
}

Thavanesi Gurayah, BOT (UDW), MOT (UKZN) https://orcid.org/0000-000I-9005-6355

Lecturer, Occupational Therapy Department, University of KwaZulu-Natal, Westville Campus

Introduction: Autism Spectrum Disorder (ASD) requires a lifetime commitment of care and imposes significant stressors on families. This study aimed to understand the lived experiences and coping strategies of parents with children diagnosed with ASD. The study addressed one of the objectives of a larger project.

Methods: An exploratory, qualitative study using purposive sampling to recruit parents of Children with ASD was used. Six individual interviews and one dyad interview provided the data for this study. Data were interpreted using thematic analysis.

Findings: The study identified two major themes namely experiences of ASD and coping with ASD. Dealing with ASD was characterised by significant challenges associated with resource limitations, poor guidance from health professionals, protracted diagnostic processes, reduced awareness of ASD and stigma for families. Parents were resilient and empowered themselves to cope with the tough journey, with support systems providing a buffer to families. Parents identified support, resources and awareness as pivotal needs. Positive ramifications from parenting a child with ASD were the development of positive personality traits, increased spiritual faith and a greater appreciation of life. The study emphasised the need for increased resources and support for families to cushion their experiences of ASD.

Key words: Autism, lived experiences, coping strategies, parents, challenges

\section{INTRODUCTION}

Autism spectrum disorder (ASD), a global phenomenon affecting I in I 60 children, is classified as a developmental disability with distinct features'. Although the prevalence of ASD in Africa is unknown, it is predicted that $2 \%$ of the South African (SA) population is affected by $\mathrm{ASD}^{2-4}$. Springer et $\mathrm{al}^{5}$, in their retrospective review of 1010 medical records in 20 I3, projected that there are over 270,000 people with ASD living in SA, with 5000 new cases per year ${ }^{5}$. Although research is limited, they found that ASD was progressively increasing, and SA is recognised as a leader in ASD research in Sub-Saharan Africa, ${ }^{6,7,8}$. The increased incidence of a child with ASD (CASD) warrants further research to reduce the burden of care and discover more efficacious interventions to promote positive outcomes for people living with children with ASD.

ASD presents with persistent deficits in social communication and interaction, and restricted or repetitive patterns of behaviour in early childhood'. A diagnosis of ASD is confirmed once impairment is noted in everyday functioning. ASD requires an enduring commitment from families given the pervasive nature of the condition ${ }^{10}$. Children present with behavioural and sensory difficulties and impaired communication and self-care ${ }^{\prime \prime}$, which have significant repercussions on daily life as the family strives to manage the child. Families alter routines and deal with the stigma from the public ${ }^{12}$, while parents sacrifice careers ${ }^{13}$. Occupational therapy intervention is aimed at moderating daily life in order to reduce the impact of the stressors on the family and the CASD.

This study informed a broader study which explored the lived experiences and coping strategies of families living with a child with autism spectrum disorder. One aspect of the study concentrated on siblings whilst this paper explored the realities of parents, with both groups originating from the same family, making it the first study in South Africa to engage parents and siblings from one family to provide unique, in-depth insights from families. This study aimed to understand the lived experiences and coping strategies of parents of a child with ASD in order to inform intervention programmes for ASD. It will supplement the local body of research and knowledge on the effects of ASD on families and facilitate more specific and relevant interventions.

\section{LITERATURE REVIEW}

In a study conducted by Divan et $\mathrm{al}^{14}$ parents often reacted with shock and distress upon receiving an ASD diagnosis. Although receiving a diagnosis allowed initial relief, greater awareness of the child's needs and access to specialised services ${ }^{15}$, the parents were faced with the challenges unique to ASD. The permanence of ASD demands a lifelong commitment of care; dealing with stressors and lifestyle changes to manage the child ${ }^{16}$. Current international and local research highlight resource limitations for healthcare and schooling, and inevitable changes within the family unit ${ }^{7,10,16-19}$. Changes included, but were not limited to, catering to the ritualistic needs of the child ${ }^{20,21}$, vocational changes of parents to accommodate the child $^{18,21}$ and social isolation of the family ${ }^{14}$.

The burden of care placed on families dealing with ASD resulted in a strain on spousal relationships and those with typically developing siblings. Given that families focused on the CASD ${ }^{22}$ and restructured daily life to meet the demands of the child ${ }^{16,17,23}$, there 
is a reduction in time available to spend on other family relationships. Family challenges extended to financial burdens given the additional costs encountered for a CASD ${ }^{10,14}$. Mothers more specifically endure a greater burden in the form of fatigue, depression and anxiety often neglecting their own needs for intervention ${ }^{24,25,26}$. Similarly, fathers are not immune from the impact of ASD.

A study in the United States measured the psychological wellbeing, pessimism and coping of 135 fathers of adolescents and young adults with ASD. The fathers of CASD had higher levels of depressive symptoms than other fathers and the overall study recommended that services be designed for fathers of CASD ${ }^{27}$. Although there is a dearth of literature in the experiences of fathers with CASD it is known that they experienced reduced quality of life, distress in that they cannot protect their CASD and experienced strain in setting up social networks ${ }^{25,27}$.

Coping is a dynamic process using cognitive and behavioural appraisal to deal with challenges which require more than an individual's available resources and necessitate an adjustment of behaviours, thoughts or emotions to facilitate coping ${ }^{28}$. Coping has two typologies and functions namely, problem-solving coping which aims to modify the person or environment to effect change, whilst emotion-focused coping aims to alter the individual's approach to the stressful environment, or reduce the adverse emotional toll on an individual ${ }^{28}$. Parents used various coping strategies to manage the child with ASD ${ }^{14}$ including distraction, problem-focused coping $^{22}$, avoidance or emotion-focused coping ${ }^{29}$. Sarria and Pozzo's ${ }^{29}$ study of 127 mothers and 90 fathers reported that mothers used more positive and problem solving strategies whilst fathers tended to use avoidant strategies Adaptive coping strategies allowed for a higher family quality of life ${ }^{30}$ since it generated effective, productive responses to stressors ${ }^{31}$ whilst avoidant coping strategies were maladaptive ${ }^{29}$. In a study of 180 families in a South African context ${ }^{16}$, it was reported that family quality of life increases with regular routines. Access to social support and respite services, which is the time away from the child, were important coping strategies that facilitated family adaptation by allowing parents time together, thereby reducing stress and social isolation ${ }^{23,}$. In the South African context, limited resources for education, healthcare and support services will challenge parental coping strategies ${ }^{32}$ and must be facilitated at the family level with support for all family members. Individual personality traits influenced the strategies employed for coping $^{33}$. Self-compassion had a buffering effect on depression and parental stress becoming a predictor for parental well-being ${ }^{33}$. Vassallo found that a positive factor in improving emotional distress involved equipping parents with a means to relate to their child whilst managing a parent's level of distress and can facilitate positive outcomes and coping with a CASD ${ }^{10,26}$. Falk, Norris and Quinn ${ }^{26}$ stress the importance of intervention that understands and acknowledges the psychological well-being of parents in a more holistic system of focusing on the parents and the child.

Positive reappraisal, in terms of creating positive meaning from one's experience, another strategy used by parents, was found both locally and internationally ${ }^{16,30}$. Local research found that positive meaning is derived from parenting the $\operatorname{CASD}^{7,19}$. Spirituality, tolerance and appreciation of life intensified and parents became more confident in their skills ${ }^{29}$. Personality traits like empathy, acceptance and patience were augmented through the experiences of adversity related to ASD ${ }^{34}$. Acceptance of the diagnosis was a positive influence on parental adjustment ${ }^{35}$. Mothers appeared to experience a higher amount of positive gain than fathers ${ }^{29}$. This is theorised to be the effect of the mother generally taking on the role of the primary caregiver thus affording mothers an opportunity for personal growth and strength ${ }^{29}$. Despite the challenges and the need to find ways to cope some parents found positive meaning in raising a $\mathrm{CASD}^{7,19}$.

\section{METHOD}

Design: A qualitative phenomenological perspective with an interpretive design steered the descriptions of the parents' experiences of having a CASD. The interpretive paradigm was conducive to conveying meaning to participants' experiences ${ }^{36}$. The study set out to explore the lived experiences and coping strategies of parents of children with ASD.

Research Context: The study was conducted in KwaZuluNatal (KZN), South Africa. Research participants were recruited via three schools for Learners with Special Educational Needs (LSEN).

Participant Selection: The research population comprised of parents with a CASD. All parents of children with ASD who attended the participating schools were invited to participate in order to acquire a diverse sample. Eligibility criteria included a confirmed diagnosis of ASD by a medical professional, and the CASD residing with the parent/s. Purposive and snowball sampling strategies were used to recruit participants. The sample size was eight parents $(n=8)$.

Data Collection: A semi-structured interview schedule was developed by extracting themes from literature on the effects of ASD on families and the coping strategies employed. Themes included coping and challenges, relationships within the family, issues around the diagnosis, and personal challenges for family members informed the questions. The relevance of the information gleaned from the interview schedule was tested in a pilot interview and found to be sufficient for data collection, as it elicited the information to answer the research questions.

Six individual semi-structured interviews including the pilot interview, and one dyad interview with both parents were conducted by the researcher.

The researcher conducted the interviews, and ensured that all participants' views were elicited, and passive participants were encouraged to actively engage. The interview was guided by an interview schedule and questions such as "what is your understanding of ASD and what problems is your child experiencing" were asked. Information from the exploratory study was included in the main data set, which is an acceptable practise if methodology remained consistent ${ }^{28}$. Interviews were conducted at venues that were convenient for the participants, such as their homes, nearby offices or the researcher's practice. External distraction was controlled by selecting quiet, private venues, and a "Do Not Disturb" sign was pasted on the door. Moreover, conducting interviews on a Saturday limited external distractions as it was not a working day, and parents came without their children. Interviews were recorded with the parents' consent.

Data Analysis and Interpretation: Audio recordings were transcribed verbatim. Thematic analysis as stipulated by Braun \& Clarke $^{37}$ was used to analyse data, which allowed identification, analysis and description of the themes contained in the data set to inform the report. Bronfenbrenner's Ecological Systems Model ${ }^{38}$ guided analysis and interpretation of data using a deductive approach. Factors that were specific to the child or microsystem ${ }^{38}$, such as the severity and type of symptoms were analysed in relation to the stressors presented to families. The individual characteristics of parents such as personality traits, coping styles and resilience were considered with regards to parental coping styles. Family characteristics such as the number of children and support systems from extended family and community (mesosystem ${ }^{38}$ ) were analysed in relation to family coping. Exosystemic factors ${ }^{30}$ that were enabling or barriers to coping such as the education system, parental employment and governmental policies and macrosystemic ${ }^{38}$ effects of beliefs, ideologies and customs were considered in relation to family coping. Lastly, the chronosystemic effects that encompass changes over time and the influence on the families' coping were evaluated.

Ethics: Approval for this study was obtained from the Biomedical and Research Ethics Committee, BREC: 065/I6, at the University of KwaZulu-Natal. Written permission was received from the Kwazulu-Natal Department of Basic Education to access schools for Learners with Special Educational Needs (LSEN) and from principals to access their learners. Only three principals consented.

All parents of children with ASD received an invitation to participate via the school. Parents who indicated interest to participate 
Table I: Demographics of families

\begin{tabular}{|l|c|c|c|c|c|c|c|}
\hline Participant (Pseudonym) & Raquel & Viola & Dakota & Thandi & Princess & Briella & Nicole / JD \\
\hline Race & Indian & Indian & Indian & African & African & African & Indian \\
\hline Number of Children & 2 & 3 & 4 & 2 & 3 & 4 & 2 \\
\hline Gender of CASD & Male & Male & Male & Male & Male & Male & Female \\
\hline Age of CASD & 16 & 12,5 & 12 & 12 & 13 & 10 & 10 \\
\hline Income Group & High & High & Middle & High & Middle & Middle & Low \\
\hline Work & Self employed & Self employed & Housewife & Employed & Employed & Employed & $\begin{array}{c}\text { Dad - employed } \\
\text { Mum - housewife }\end{array}$ \\
\hline Religion & Hindu & Hindu & Christian & Christian & Christian & Christian & Hindu \\
\hline
\end{tabular}

were contacted for an interview. At the interview, consent was discussed with parents and issues of confidentiality, ethical responsibilities of the researcher, the use of pseudonyms to protect identities and their right to withdraw were highlighted. Trustworthiness with respect to credibility, transferability, dependability and confirmability as identified by $\mathrm{Guba}^{39}$, were maintained with thick descriptions of the context and participants, bracketing, a reflective diary, and peer discussions with researchers.

\section{FINDINGS}

The demographics of the participants are tabulated above. All families resided in urban areas. All children, except one child, was enrolled at an LSEN school. One CASD was from a single parent family and only one child with ASD was female. The children had varying degrees of severity of autism spectrum disorder.

The data revealed two themes. The first theme described the lived experiences of parents with a child with ASD and the second related to the efforts to cope when managing a child with ASD. (See Table I above).

\section{THEME I: LIVED EXPERIENCES OF PARENTS OF A CHILD WITH ASD}

Illustrated in Figure I below are the categories which captured the daily experiences of parents navigating ASD.

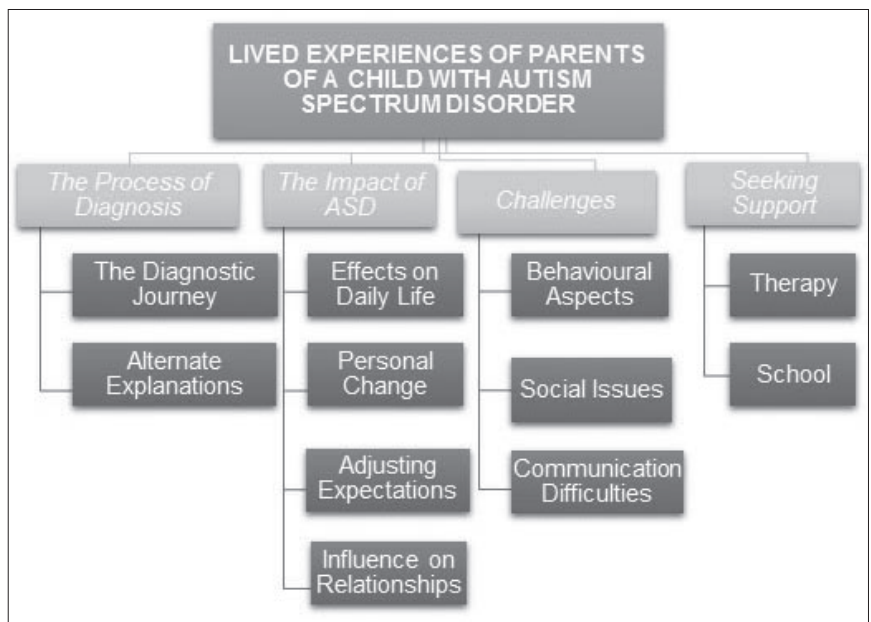

Figure I: Theme I: Experiences with Autism Spectrum Disorder

\section{The Process of Diagnosis}

The diagnostic journey was protracted, emotional and filled with contradictions. Parents, already questioning their own capabilities, faced professionals who presented differing opinions. Even when I came with a letter that said he is autistic from Dr Mary, Dr. Grey said no he is a slow learner (Princess). All participants except one heard the term ASD for the first time. I was watching Oprah... they were talking about autism... all the signs were there on my son (Briella).
In Dakota's case, diagnosis took two years following numerous consultations with health professionals. Jonathan was angry with professionals for the late diagnosis which took three years. I felt that these doctors didn't pick up anything (Jonathan). Interestingly, the diagnostic process was less than a year in the private sector, in contrast with the public sector which took years. In this six months for me it's better because I have the medical aid...can you think like more as a person who doesn't have money? (Princess)

Parents reported that interactions with health professionals defined their experiences with ASD, and professional attitudes had a profound impact on parents. Viola's paediatrician asked her: why can't you discipline your child, which compounded an already stressful situation. Empathetic and knowledgeable professionals were a protective factor for parents and provided support during the journey. Emotionally connected, empathetic, reassuring, supportive...they understood the impact, the enormity of what that [ASD] actually meant (Viola). Guidance and support after diagnosis was minimal, leaving parents to fend for themselves. It appeared that professionals themselves lacked adequate knowledge on the way forward. One parent consulted a psychologist for two years, receiving no direction about schooling, and independently approached a LSEN school for placement for her child. Viola's comment: once the parent is given the support... resources, everything moves much faster... once that becomes a stumbling block...it takes much longer to get going illustrated the importance of timeous professional support.

The ASD diagnosis evoked negative emotions of shock, blame, denial, and depression, leaving parents overwhelmed by the magnitude of the situation. I went into... severe depression...I used to get panic attacks (Viola). I was thinking to hang myself(Princess). Parents felt relieved as they understood their child's behaviour and could move forward. Dakota explained: I did feel relief.. I I understand... I know he's not a naughty child. The realisation that parents were not to blame was liberating.

Cultural explanations for ASD included ineffective parenting and poor discipline, which frustrated and angered parents. Since there was no visible disability, the notion of poor discipline was strengthened, and parents were exasperated by this. I got three children, the other two are perfectly well disciplined. Can you really think it's an issue of discipline? (Viola). Certain cultures favoured community discipline, thus exposing child to abuse. If a child misbehaves, it's like you don't teach the child correctly how to behave...I know he can be abused (Thandi). Frustration with cultural practices was noted, and two parents did not allow traditional ceremonies. I did not approve... my son ended up not going there... but then I'm also a nurse... it's hard for me to actually believe that he is a sangoma (Thandi).

Religious explanations rationalised that ASD was a result of witchcraft and demon possession. I went to a Sai Baba place... she said she's taking out a demon... the pastor came and said he's taking out another demon (Raquel). She had problems when she was two months old with witchcraft (Nicole). Other families believed that the child was a gift from God, as Princess declared God gave me another special child.' 


\section{The Impact of ASD}

All parents reported that ASD was pervasive and life revolved around the CASD with a 'help him' attitude prevailing as parents reorganised their lives. My mind set was just helping him (Raquel). If you have a child with autism... your life just stops (Princess), depicted the immense sacrifice for the child. Acceptance is one thing. It goes beyond acceptance (Raquel), personified the life-long commitment to a CASD.

Living with a CASD generated positive and negative changes for parents. One well-resourced parent stayed home, whilst another sacrificed her career. I quit work going into the height of my career (Viola). Nonetheless, there was personal gain, via emotional and spiritual growth. This overshadowed sacrifices as parents reported that they viewed life differently and appreciated its value. Positive growth resulted in personal transformation, fostering characteristics such as perseverance, tolerance, understanding, compassion, patience and hope. It [ASD] made me stronger... to deal with a child... with so many different challenges (Dakota). I learnt to appreciate children (Thandi).

Despite positive gains, significant emotional turmoil was evoked as parents adjusted to the CASD, whilst some struggled to adapt and others accepted their realities. The responsibility and constant struggles left some mothers vulnerable. It will be better...I should just go away...that's the kind of break I need... love them, but don't be with them (Thandi). Parents without spousal or extended support struggled the most with the difficult realities, with boarding school being considered in one case. When it comes to my son everybody just shutdown. Everybody...my husband...everybody. I was like stressed on my own... it was stressful... painful and I didn't know where to go (Princess).

Parents adjusted their expectations of the child, finding joy in small achievements which were considered huge accomplishments. One day if he could just get out of napkins...just learn to say his name, it will be huge (Viola). Academic expectations were replaced by a need for independence in activities of daily living to moderate life for the CASD and family. All parents shared apprehensions with adjustment to changing life roles such as those in adolescence. I'm worried how he's going to adapt sexually (Raquel).

The demands of ASD affected spousal relationships. Initially, blaming each other caused friction between spouses, but this dissipated as acceptance of ASD ensued. I was blaming myself... the family becomes dysfunctional, you blame your husband (Raquel). A change to the couple relationship was unavoidable due to the investment of time with the CASD. There is no time together as a couple... that stopped after Sipho was born (Thandi). Two couples experienced a breakdown in their marriage, but stayed together. One couple separated due to the stress related to the CASD.

Relationships with the neurotypical children were compromised as parents were mostly involved with the CASD. Mothers expressed guilt about spending less time with neurotypical children, but explained that neurotypical children understood their commitments. I can't remember him at seven... eight... nine, I remember the sadness in his face, but I can't remember anything (Raquel). Only one neurotypical child reported to his parents that he felt "left out and unloved" as Nicole explained.

Relationships with extended family were altered. Support was withheld when understanding of ASD was limited, resulting in a loss of extended family relationships. My own mother asking how do you live with this...I mean how do you manage because really this is too much (Thandi). Only one family received the support of the extended family, whilst two other families were able to talk to extended family if required. Dakota expanded on the importance of understanding: Everybody used to be upset that we were not coming... but everybody got to understand him...they okay with us not coming.

\section{Challenges}

Challenges were a daily occurrence, and behavioural problems were persistent. Early behaviours included physical aggression, foul language, head-banging, not sharing toys, and rolling on the floor. $\mathrm{He}$ never played with the other children... he was biting... using languages (Dakota). Behavioural problems were the most challenging aspects for parents, and included physical aggression, destructive behaviour, tantrums, meltdowns, screaming, crying, enuresis, and smearing faeces. Princess expressed her desperation: he cries...just screams... breaking things in the house. Self-stimulating behaviour and fascination with a single object did not cause undue concern for parents.

Social challenges influenced the lives of the families. Some children preferred to remain home, whilst others enjoyed outings. Sadly, all were overstimulated in crowds, resulting in meltdowns. It's the sounds or the lights...he doesn't like high volumes... he will get a meltdown immediately (Briella). This made social outings difficult, but parents learnt through experience how to manage the outings.

Communication difficulties arose from poor reciprocal and spontaneous communication. If you say "hello Steve, how are you?" He is trained to say, "I am fine thank you". "How was your day at school Steve? He will keep quiet (Viola). Communication improved with time, especially after enrolment at school. Interestingly, the lack of communication was accepted and acknowledged by parents. Acceptance seemed to quell stress in the parents. Thandi explained: I'm not going to get any communication in Sipho...I understand that very well.

\section{Seeking Support}

Parents strived to improve life for their child, and sought various interventions. Parents with more resources accessed diverse interventions, whilst under resourced parents were limited to minimal government services. Only one family accessed speech therapy and audiology privately, four families were reliant on school services for speech therapy and occupational therapy, and two families had access to the majority of interventions. Table // below presents the

Table II: Interventions accessed by parents

\begin{tabular}{|l|l|}
\hline INTERVENTION TYPES & THERAPY MODALITIES \\
\hline Traditional & $\begin{array}{l}\text { occupational therapy, speech therapy, } \\
\text { physiotherapy, applied behavioural } \\
\text { analysis (ABA), kinesiology }\end{array}$ \\
\hline Medical & stem cell therapy, medication \\
\hline Alternative & $\begin{array}{l}\text { Mind Stretch, horse riding, individual } \\
\text { tutors, natural products, colon } \\
\text { cleanse, gluten and casein free diet }\end{array}$ \\
\hline
\end{tabular}

\section{different interventions.}

Dedicated schools for ASD were limited. The main thing that there is very limited facilities... there is no specific facility for autistic children the equivalent of the school in the next city (Viola). Furthermore, skills and knowledge of educators were sometimes inadequate. They were not empathetic, did not harness the potential of the child, and management of the child was poor, which caused emotional trauma for the family. Viola expressed her negative experiences with the educators: more than a journey away with my child in this autism, is to put up with all the ignorance. She was often reminded that resources to manage ASD were not available at the LSEN school.

In contrast, schools with specialised units facilitated improvement in the child, especially with communication. These schools were teaching sign language (Makaton) to facilitate communication and offered support to parents. So it's getting easier as he's getting better from being at school and learning skills (Princess). The children thrived and parents did not receive complaints about behaviour. In fact, educators assured parents who anticipated bad behaviour that they (educators) were equipped to manage situations.

\section{THEME 2: EFFORTS TO COPE WHEN MANAGING A CHILD WITH ASD}

This theme described the sources of parental stress and their responses to cope with daily life. See Figure 2 on page 47. 


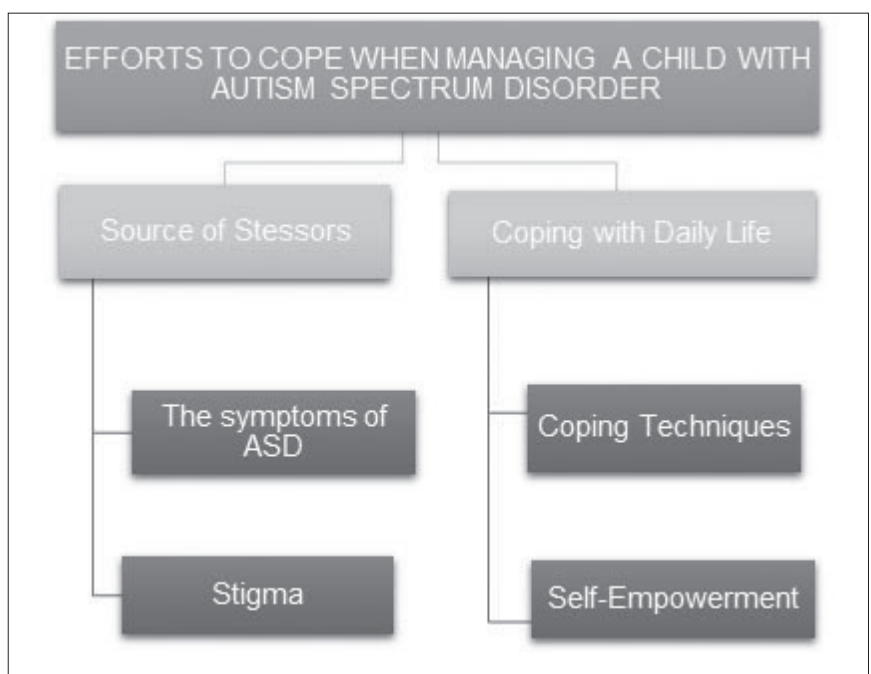

Figure 2: Theme 2: Coping with Autism Spectrum Disorder

\section{Source of Stressors}

Meltdowns and destructive behaviours aimed at people and property, which sometimes incurred financial costs, triggered significant stress for parents. Other behaviours, seemingly minor, but causing significant stress, were prolonged episodes of crying and screaming by the CASD. Mothers reported that the child responded to their fathers' commands to behave, and wondered if boundaries would be beneficial, as the child appeared to have an awareness of expectations. I've noticed that my son is very scared of my husband. He won't do these things when my husband is around, he behaves much better (Thandi).

Difficulties relating to self-care activities were distressing, especially as parents were aware of their own mortality. When he comes out of the bathroom... he doesn't care who's there. He will just run...now he's bigger (Dakota). How long we will live and who will take care of her? (Nicole).

Sensory overstimulation resulted in meltdowns which reinforced decisions to stay home. I can't let him go to parties... if he gets a meltdown...people won't understand (Briella). This limited socialising opportunities for the CASD and the family.

Difficulties with communication were another stressor as parents did not know what was wrong. It's not easy to see your kid from a normal functioning kid, then not know... if he's hungry, if he needs to go to the toilet (Raquel).

Changes to routine generated stress for the CASD. She goes to school with the school transport, if the transport doesn't come she wouldn't want to go (Nicole). Families had to ensure that routines were in place, but sometimes had no control over the situation.

The demands of caring for a CASD was another source of stress for parents. The extended involvement with the child encroached on time for other activities and relationships, limiting much needed respite. Access to specialised caregivers and respite services can facilitate the parents' time spent away from the child. Jonathan thought that a trained person and as Nicole stated with experience, could allow families some respite. Without social support, a result of limited awareness of ASD in the extended family, opportunities for respite were limited. Families with adequate support engaged in regular respite activities, which allowed parents time together without the child. My husband keeps him...l go out, or maybe we both go out, then the helper keeps him (Dakota). Difficulties with acquiring a caregiver increased demands on the parent. I'm having problems with caregivers... they will be ok for the first 3 months, and then after that you will see that they don't understand at all. (Thandi).

Behaviours of the CASD in public aggravated parental distress which was directly linked to negative public reactions. Parents were accused of poor discipline and others tried to discipline the child, or insisted that parents follow through with discipline. Limited awareness of ASD and the 'normal' appearance of the child reinforced public opinion of poor discipline. I don't go with him to church because they don't understand. . . they say I must let him sit down (Princess). Consequently, parents refrained from social activities to avoid these reactions, and because they struggled to manage their child's behaviour. Public opinions exposed families to stigma, which intensified with the self-imposed social isolation. Thandi described her own parents: Sipho wants to shake hands with them... they just like pull back and don't talk.

\section{Coping with Daily Life}

Parents cultivated coping strategies to mediate the effects of living with a CASD. Distraction for the CASD, such as watching television, and calming techniques were favoured. Sometimes bribery worked. We buy her a juice... she likes chocolates, we just have to bluff her with something (Nicole). Practical ideas were adherence to routines or allowing the CASD peculiarities such as wearing a specific T-shirt. Strategies were not always successful. If it was a big thing I'll try and calm him down, but if it's the screaming and the crying... you try to understand or hug him or you just...I just don't know but I manage (Briella). Identifying triggers and preventing a meltdown was essential. I watch behaviour...I could see... certain cues with him (Viola). Sometimes the only thing for the parent to do was to walk away at that time.

Preparation for alterations in routines and social outings were necessary to prevent outbursts and anxiety. Princess successfully had a 'meltdown free' outing after educators provided advice. They tell me I must try and tell him before we leave home, where we going, why we are going there... after going there, we will be going there. In addition to learning appropriate management techniques, parents used avoidance of potentially hurtful situations to facilitate coping. Thandi elaborated on staying away from harmful comments: If he stays away from everyone and they stay away from him... that's a coping mechanism for me. In contrast, other families did not limit socialisation, and grew to ignore public reactions, which helped them cope with the situation.

Cognitive strategies involved choosing effective solutions whilst managing the emotions that accompanied stress. You just automatically respond... without even thinking it through... I must think this through and not feel like so emotional (Viola). Thinking about situations and formulating a response in advance, alleviated the stress in the situation. Working was a reprieve from the situation at home. When I'm at work I feel better... I overwork (Princess).

Spiritual and religious faith assisted with acceptance and stress reduction. I pray all the time... ask God to give me patience and to help this child...I'm waiting for a miracle (Dakota). This instilled hope, thereby enabling coping and acceptance.

Families facilitated coping through discussions about crises and alternate solutions. Self-empowerment was important for families who increased knowledge and skills through internet searches, talking to professionals, and discussions with others. I started to google... what kind of a person that is autistic and all those things (Briella). Two parents attended workshops and additional training. One parent became certified in Applied Behaviour Analysis (ABA) and assisted other families. I give them books, I photocopy ABA manuals (Raquel). The desire to assist others and advocate for children living with ASD was a means of coping. All participants yearned for information and support groups. A support group... to interact with other parents that have a similar case... to pick up ideas from them (JD).

Once parents reframed their realities with their CASD through coping skills and acceptance, their experiences adapted positively. Viola's expression of her journey epitomised this: You scared of heights and somebody's telling you to climb a chain ladder on the wall of a cliff. By the time you get to the top you realise even your fear of heights has left you... when you look out from there you can breathe... you can see the scenery and you can see like a whole new world.

\section{DISCUSSION}

This study highlighted the significant challenges of families living with a CASD and their efforts to negotiate daily life during this 
journey. Concurring with previous literature ${ }^{10,14-16}$, challenges related to the diagnostic process, health professionals' negative behaviours, resource limitations, reduced awareness about ASD, negative public perceptions and the presenting symptoms of ASD. The high burden of care and restructuring of family life was well documented ${ }^{18,22,40}$, and parents in this study reported that professional and personal lives were disrupted as they tried to make sense of the unknown realities of ASD. Parents asserted that lifestyle, career and relationship changes were unavoidable, and routines and activities were structured to accommodate the child, phenomena also noted in previous literature ${ }^{14,23}$. Family coping was facilitated by shifting focus to the child, as families mobilised and adapted to the uniqueness of their situations, likewise noted in previous research ${ }^{10}$. Perseverance and resilience emanated from families ${ }^{7,10}$ against the backdrop of resource limitations ${ }^{18,22}$. Positive fulfilment was attained by parents in this study, a finding noted previously in local literature ${ }^{7,19}$. Whilst the CASD impacted on the family's microsystem, numerous external entities influenced the family and the child, which aligned with Bronfenbrenner's Ecological Systems Mode $^{38}$, which explained human development along five socially organised subsystems that reciprocally influence each other, and are in a constant state of interaction.

The exosystems included systems indirectly influencing the CASD like government and economic policies and health and education systems ${ }^{38}$. Exosystemic effects on the CASD and the family manifested from the outset as parents encountered frustrating professionals' behaviours, protracted diagnostic processes, and limited support, a scenario encountered in recent literature $\mathrm{e}^{10,14,40}$. Essentially, the inadequacies of health professionals altered realities of families and the CASD. When professionals failed to identify symptoms of ASD to formulate a diagnosis, either through insufficient knowledge or being non-committal, the arduous journey was extended, intervention was delayed, and the family's quality of life was affected. Parents reported dissatisfaction with professionals' behaviours, and longed for support which was absent or limited, findings supported by previous literature ${ }^{7,10,22}$. Clearly, knowledgeable and supportive professionals can ease the journey by providing support, thus exosystemic changes are critical. This notion of support and knowledge was extended to educators as well.

Supportive and knowledgeable educators encouraged parents and facilitated improvement in the child by developing functional skills ${ }^{14}$. In contrast, educators with sparse knowledge and inadequate skills managed the child poorly and curtailed development. In such cases, early symptom recognition was hindered since educators, although strategically placed, were unable to identify the child's problems. Literature supported the ramifications of poorly trained educators ${ }^{14}$ which propagated the cycle of late identification, delayed intervention and poorer outcomes, further strengthening the argument for targeted exosystemic changes.

The microsystem ${ }^{30}$ directly influenced the CASD and included the family, school, home, religion and the neighbourhood. Reciprocal interaction between the exosystem and the microsystems resulted in multifaceted parental stress which directly related to the CASD. Parents reported that stressors manifested pre-diagnosis and that diagnostic confirmation brought relief as the behaviours of the CASD could be understood and a way forward was actualised, which concurred with recent studies ${ }^{10,19}$. Relief was displaced by a barrage of negative emotions as the magnitude of the situation evolved, supporting findings of previous studies ${ }^{7,10,22,}$. Parents were overwhelmed by the constant burden of care, and some struggled to adapt to the demands of the CASD, which was well documented in the literature ${ }^{30,33}$. This was partly due to the limited guidance that parents received from health professionals, leaving them uncertain about the way forward. Consequently, parents did not have the internal resources, for example how to deal with adverse behaviours of the CASD or the external resources, like support from stakeholders such as health and education to ease their journey.

Influencing changes in the exosystem can be effected by occupational therapists through collaboration with doctors, allied medical professionals and educators about our clients with ASD and by providing resources (through therapy for the CASD and support programmes) for parents. An earlier diagnosis will result in early intervention and correct placement of the child. Awareness is imperative to effect change and occupational therapists have the opportunity to advocate on behalf of the families. Equipping educators with skills and knowledge will enhance progress for the CASD and occupational therapists must be involved at the school level. Exosystemic changes will impact positively on quality of life for the family and the CASD.

The current study concurred with other studies regarding parental commitments to the CASD and the sacrifice of time with neurotypical children ${ }^{19,21}$ and spouses ${ }^{12,14,17}$. The repercussions thereof was a disruption in relationships with other family members which strained an already stressed family system. There was the inevitable loss of the couple relationship ${ }^{14,17}$ and disrupted relationships between parents and neurotypical children, thus invoking guilty feelings within parents, especially when children reported unfair treatment ${ }^{14}$. Opportunities for respite can be created with support from the extended family or services of a skilled caregiver. Microsystemic intervention from occupational therapists such as empowering caregivers with knowledge and skills will satisfy parental needs for suitably qualified caregivers, as well as creating public awareness. This will impact on the roles of the extended family by increasing support and training opportunities of caregivers. Studies indicated that social support was important to facilitate coping and adaptation in families by allowing for respite with other family members ${ }^{21,34}$. Respite served to reduce parental stress ${ }^{29}$. The high cost of $\operatorname{care}^{18}$ for the child limited parental access to support or respite services. Parents will benefit from emotional support services, thus change must be motivated at an exosystemic level. Occupational therapists are frontline practitioners to influence the microsystem with the opportunity to provide support by way of teaching practical skills to deal with daily needs of the CASD and to equip parents with skills to cope with daily life.

The ethos of sacrifice was not without consequences. As indicated in previous literature, the costs of caring for a CASD were high $^{12}$ which restricted access to therapy and other needs for the CASD and family. Resources needed for a CASD, such as therapies, caregiving, special schooling and medical expenses were limited, and services were unaffordable, engendering stress and feelings of guilt in parents ${ }^{14,23,34}$. Parents accessed a multitude of therapies if financially viable ${ }^{34}$. However, resource limitations for education and healthcare were a reality in $\mathrm{SA}^{32}$ thus straining the family system. Families faced inadequate and limited services and lengthy waiting lists for school ${ }^{32}$. The need for advocacy for dedicated services for ASD was noted at an international and local front ${ }^{7,22}$ and was essential to parents in this study. Changes should be instituted at the exosystemic level to procure suitable services for ASD. Changes must be made at a governmental level and relevant stakeholders must mobilise to make a difference. Creating awareness is key to effect change at a higher level but direct address to effect change to existing policies is imperative.

Parents in the current study experienced similar challenges cited in other studies, which related to behavioural challenges, considered the most problematic ${ }^{11}$, communication ${ }^{12}$ and socialisation $^{10,14,17}$. Coping strategies alleviated stress for the family. Successful strategies involved preparing a child for events, maintaining routines, and keeping the child happy" , whilst immersion in work was respite from the home situation, a phenomenon noted in the literature ${ }^{10,13,29}$. Social isolation was used to manage challenging behaviours ${ }^{10}$, which had positive and negative consequences. Sensory overload provoked tantrums, meltdowns and elicited negative public reactions towards the child's behaviour, thereby cultivating stigma, hence families limited socialising to reduce stress. However, as seen in other studies ${ }^{14}$, this served only to strengthen stigma and deprived the child of opportunities to socialise, which was hindered by cultural opinions. Parents must be empowered with skills to manage the behaviours of the CASD, and awareness must 
be facilitated to reduce stigma, which is within the domain of the occupational therapist.

Cultural perceptions of poor discipline and ineffective parenting accounted for negative public reactions, a finding supported by local and international research ${ }^{7,19,22}$. A SA study found that ineffective discipline was a western belief ${ }^{21}$. Being bewitched, an African cultural perception strengthened stigma ${ }^{21}$ and propagated the cycle of social isolation. The current study found that children with ASD were thought to be possessed by demons in Hinduism and Christianity, causing feelings of shame and sadness in parents, and contradicted other findings that related to demon possession to the African culture ${ }^{7}$. Incongruities related to culture may be a result of the unequal representation of race groups, and the small sample in this study. Nonetheless, awareness will be beneficial to enhance understanding on a sociocultural level.

Intervention at the exosystemic level can influence positive microsystemic change by increasing awareness of ASD, and facilitating understanding from a health perspective. Anticipated repercussions include reducing negative public reactions and stigma ${ }^{14}$. Demystifying ASD will serve to improve social support for parents as understanding and tolerance is developed. Apart from stigma, awareness can increase early identification of ASD. Awareness and support were cited as important to ease the journey for families, along with information and guidance to help the CASD, and support groups to facilitate coping ${ }^{11,14,34,40}$, all sentiments echoed in this study. Support groups for all family members were perceived by parents to have a buffering effect on stress, through opportunities to share ideas, and were linked to increased life satisfaction in previous studies ${ }^{40}$. Support benefits will cement realities from the beginning. Apart from gaining knowledge and skills, this can be a cathartic opportunity for family members, and an option for respite.

Families faced adversity, related to limitations of access to resources, education, professional support, stigma, religious and cultural views. They were victims of occupational injustice, which occurred when physical, social, economic or cultural resources were denied to a group of people, who are subsequently excluded from opportunities to be engaged in meaningful occupations ${ }^{41}$. Since families endured these adversities through factors beyond their control, they were casualties of occupational deprivation, which meant being precluded from engagement in necessary or meaningful occupations ${ }^{41}$. Seen in the context of ASD, the CASD cannot access essential therapeutic and educational services, and parents, by virtue of limitations, struggled to provide opportunities for the CASD. Occupational therapists must identify systemic barriers within the microsystem and exosystem, and effect change to promote occupational justice for this marginalised population to enable meaningful engagement.

Living with ASD was not governed entirely by adversity, and personal gain was reported by all parents. The determination to make life easier for the child fostered positive growth and acquisition of positive personal traits, which occurred in the face of adversity $10,30,34$. The assimilation of these traits moderated stress, promoted resilience in families and equipped parents to handle situations. As noted in other studies, life became easier over time as the child matured and parents honed their management skills ${ }^{7}$ and acceptance of ASD by parents reduced stress as they engaged with caring for the child ${ }^{18}$.

\section{Recommendations}

From the findings it is clear that professionals need to understand ASD and enhance their own ASD specific skills, especially with the vulnerability of this population. Curriculums for health professionals must include more focused knowledge and training to enhance and update skills.

Awareness will promote understanding and reduce negative perceptions, thereby moderating stress for families and increasing opportunities for support. Family needs must be understood by professionals, interventions should be tailored accordingly and directed at a family level. Limited resources and access thereof highlighted the need for advocacy on behalf of these families. System changes need to effect resources such as schooling, healthcare and therapy services, and must emanate from a governmental level. To facilitate this, awareness and research to provide updated information, and partnership with advocacy groups will direct change. Training curricula of teachers should include ASD identification and management.

Occupational therapists must promote occupational justice by targeting microsystemic and mesosystemic barriers to enable meaningful engagement. Occupational therapists must understand the encroachment of the effects of ASD into all systems and intervene holistically.

Future research should be conducted in rural areas where a large proportion of the population lives.

\section{Limitations of the study}

The small sample size and geographical context limit transferability to the broader population.

\section{CONCLUSION}

This study explored the lived experiences of parents with children living with ASD and their efforts to cope with their new realities. ASD presented an immense burden to families as it introduced significant, constant stressors that were expected to last a lifetime. Families were confronted with protracted diagnostic processes, the impact of having a CASD, challenges related to the symptoms of ASD and seeking support on their journeys. Efforts to cope were complicated by resource limitations, financial burdens, limited skills to deal with symptoms of ASD and stigma due to reduced awareness. Distress was thus amplified as they were trying to understand their CASD, and repercussions impacted on all spheres of family life. In response to this, and driven by the need to improve the quality of life for the CASD and the rest of the family, parents formulated coping strategies to adapt to their new realities. This was no easy feat as parents received little guidance in this regard but were driven to make changes.

Despite the adversities, positive meaning and fulfilment was derived from parenting a CASD. Parents in this study demonstrated astounding resilience and perseverance in the face of adversity.

The role of the occupational therapist should be to support parents during this process, and advocate change at the microsystemic and mesosystemic levels, to reduce the burden of care and improve quality of life for this population.

\section{REFERENCES}

I. WHO. Autism Spectrum Disorders fact sheet. Available from: http:// www.who.int/mediacentre/factsheets/autism-spectrum-disorders/ en/ (I 7 July 2017).

2. Ametepee LK and Chitiyo M. What we know about Autism in Africa: A brief research synthesis. The Journal of the International Association of Special Education. 2009; I0(I): I I-I3.

3. De Vries P. Autism in an African context. University of Cape Town News. Interviewed by Boonzaier L on $17^{\text {th }}$ October 2017. (Accessed https://www.news.uct.ac.za/article/-2017-10-10-autism-in-anafrican-context (2 $2^{\text {nd }}$ March 2019).

4. South African Government. World Autism Day Awareness. South Africa. https://www.gov.za/speeches/world-autism-awarenessday-20l7 (16 November 2017).

5. Springer PE, van Toorn R, Laughton B and Kidd M. Characteristics of children with pervasive developmental disorders attending a developmental clinic in the Western Cape Province, South Africa. South African Journal of Children. 2013: 95-99. https://doi.org/10.7/96/SAJCH.530.

6. Abubakar A, Ssewanyana D and Newton C R. A systematic review of research on autism spectrum disorders in sub-Saharan Africa. Behavioural Neurology. 2016. https://doi.org/10.1 I55/2016/3501910.

7. Fewster DL. A qualitative study to understand the experiences and coping processes of primary caregivers of children with autism spectrum disorder. MA thesis. University of KwaZulu-Natal. 2014.

8. Wilford A. Cultural variations in behaviours related to ASD in South African children. Paper presented at the HSRC Social Science Re- 
search conference, 2012

9. Carpenter L. DSM-5 Autism spectrum disorder. Washington; 2013. https://depts.washinton.edu/dbpeds/ScreeningTools/DSM-5(ASD Guidelines). Feb 2013.pdf (7 October 2017).

10. Vassallo T. "It's such a battle": a phenomenological account of raising a child on the autistic spectrum; a battle with bureaucracy and behaviour. Plymouth Scientist. 2016; 9(I): 229-5I .https://org/bcur. org/journals/index.php/TPSS/article/view/558. (3 May 20I7).

II. Ludlow A, Skelly C and Rohleder P. Challenges faced by parents of children diagnosed with autism spectrum disorder. Journal of Health Psychology. 2012; 17(5): 702-II.

http://journals.sagepub.com/doi/I0. I I 77/ I 359 I053 | | 4222955. (23 September 2017).

12. De Pape A-M and Lindsay S. Parents' Experiences of Caring for a child with autism spectrum disorder. Qualitative Health Research. 20I5; 25(4): 569-83.

http://journals.sagepub.com/doi/I 0. I I 77// 0497323 I4552455. (7 July 20I7).

13. Matthews RA, Booth SM, Taylor CF and Martin T. A qualitative examination of the work-family interface: parents of children with autism spectrum disorder. Journal of Vocational Behaviour. 201 I: 79(3): 625-39. https://dx.doi.org/10.1016/j.jyb.201 I.04.010. (Accessed 20 May 2017).

14. Divan G, Vajaratkar V, Desai MU, Strik-Lievers L and Patel V. Challenges, coping strategies, and unmet needs of families with a child with autism spectrum disorder in Goa, India. Autism Research. 2012; 5(3): 190-200. https://doi.org//0.1002/aur. 222.

15. Calzada LR, Pistrang N and Mandy WPL. High-functioning autism and Asperger's disorder: utility and meaning for families. Journal of Autism and Developmental Disorders. 2012; 42(2): 230-3. https://doi.org/10.1007/s I0803-0I I-I238-5.

16. Schlebusch L. Families raising a child with autism spectrum disorder: determining the relationship between family routines and family quality of life. PhD thesis. University of Pretoria; 2015.

17. Bashir A, Bashir U, Lone ZA and Ahmad Z. Challenges faced by families of autistic children. International Journal of Interdisciplinary Research and Innovations. 2014; 2(I): 64-8. https://doi.org//0.4I03/AJOP.AJOP_4_I8.

18. Fletcher PC, Markoulakis R and Bryden PJ. The costs of caring for a child with an autism spectrum disorder. Issues in Comprehensive Pediatric Nursing. 2012; 35(I): 45-69. https://doi.org//0.3109/0I460862.2012.645407.

19. Matenge B. An exploration of the lived experiences of mothers raising children with autism. MA thesis. University of Cape Town. 2013.

20. Johnson LN, Rodriguez D. Children with autism spectrum disorder at a pediatric hospital: a systematic review of the literature. Pediatric Nursing. 39(3): |3|-4|; $20 \mid 3$.

21. Dawson N. An ecological perspective on parents' experiences of having a child with autistic spectrum disorder (ASD) in the South African context. MA thesis. University of Witwatersrand. $201 \mathrm{I}$.

22. Hoogsteen L and Woodgate RL. Centering autism within the family: a qualitative approach to autism and the family. Journal of Pediatric Nursing. 2013; 28(2): 135-40. http://doi.org/10.1016/j.pedn.2012.06.002. (II April 20I7).

23. Shaffer CM. Parenting stress in mothers of preschool children recently diagnosed with autism spectrum disorder. PhD thesis. The State University of New Jersey. 2012 https://doi.org/I0.7282/T3GX49HQ. (I2 June 2017).

24. Larson E. Ever vigilant: maternal support of participation in daily life for boys with Autism. Physical and Occupational Therapy in Paediatrics. 2010; 30(I): 16-27. http://doi.org// 0.3 109/01942630903297227. (I March 2019).

25. Dardas LA. Stress, coping strategies, and quality of life among Jordanian parents of children with autistic disorder. Autism-Open Access. 20I4; 04(0I): I-6. https://doi.org/I0.4I72/2I65-7890. I000I 27.

26. Falk NH, Norris K and Quinn MG. The factors predicting stress, anxiety and depression in the parents of children with autism. Journal of Autism and Developmental Disorders. 2014; 44(I2): 3185-3203. Available from: https://doi.org/10.1007/s 10803-014-2189-4. (I I January 2017).

27. Hartley, Sigan L, Seltzer, Marsha Mailick, Head Lara and Abbeduto Leonard. Psychological well- being in fathers of adolescents and young adults with Down syndrome, fragile $X$ syndrome, and autism. FARE Family Relations. 2012. 6I(2): 327-342.

http://doi.org/I0.1 I II/j.174I-3729.201 I.00693.x. (28 February 2019).

28. Lazarus RS. Coping theory and research: past, present, and future. Psychosomatic Medicine. 1993; 55: 234-47.

http://doi.org/I0.1097/00006842-199305000-00002. (27 January 2017).

29. Sarriá E, Pozo P. Coping strategies and parents' positive perceptions of raising a child with autism spectrum disorders. In Fitzgerald M, editor. Autism Spectrum Disorder-Recent Advances. InTech Openaccess, 2015: 5I-79. https://doi:10.5772/58966. (17 June 2017).

30. Predescu E and Şipoş R. Cognitive coping strategies, emotional distress and quality of life in mothers of children with ASD and ADHD - a comparative study in a Romanian population sample. Open Journal of Psychiatry. 2013; 3: II-7. https://doi.org/I0.4236/ojpsych.20I3.32A003. (27 January 20I7).

31. Hudson K. Coping complexity model : coping stressors, coping influencing factors, and coping responses. Psychology. 20।6; 7: 300-09. https://doi.org/I0.4236/psych.2016.73033. (8 February 2018).

32. Department of Basic Education and UNICEF. Study on children with disabilities from birth to four years. 20I5. https://www.unicef. org/southafrica/SAF_resources_childdisability0to4.pdf. (2I January 2018)

33. Neff KD and Faso DJ. Self-Compassion and Well-Being in Parents of Children with Autism. Mindfulness. 20I5; 6(4): 938-47. https://doi.org/I0.1007/s | 267/-014-0359-2.

34. Altiere MJ and von Kluge S. Searching for acceptance: challenges encountered while raising a child with autism. Journal of Intellectual \& Developmental Disability. 2009; 34(2): I42-I52. https://doi.org/I0.1080/I3668250902845202. (20 January 20I7).

35. Jones L, Hastings RP, Vasiliki T, Keane L and Rhule N. Child behavior problems and parental well-being in families of children with autism: the mediating role of mindfulness and acceptance. American Journal on Intellectual and Developmental Disabilities. 20 I4; I I 9(2): |7|-85. http://doi.org/10.1352/1944-7558-I 19.2.171. (I December 2017).

36. Thanh NC, Thi T and Thanh $L$. The Interconnection between interpretivist paradigm and qualitative methods in education. American Journal of Educational Science. 20I5; I (2), 24-27: http://www. aiscience.org/journal/ajes (Accessed I0 March 2018).

37. Braun V, Clarke V. Using thematic analysis in psychology. Qualitative Research in Psychology. 2006; 3:77-10I. https://doi.org//0.1 I91//478088706qp063oa. (8 April 2016).

38. Bronfenbrenner $U$. Ecological models of human development. In: Guvain M, Cole M, editors. Readings on the development of children. New York: Freeman, 1994: 37 - 43.

39. Guba EG. Criteria for assessing the trustworthiness of naturalistic inquiries. Educational Communication \& Technology. 198I; 29(2), 75-9I. https://doi.org//0.1007/BF02766777.

40. Dzubay SK. Parental grief, coping strategies, and challenges when a child has autism spectrum disorder. MA thesis. University of Wisconsin-Stout. 20I I. http://citeseerx.ist.psu.edu/viewdoc/ summary?doi= I0.1.I.390.1389. (20 May 2017).

4I. Townsend E and Wilcock A. Occupational justice and client-centred practice : A dialogue in progress. Canadian Journal of Occupational Therapy. 2004; $7 I$ (2): 75-87. https://doi.org//0.I I77/00084 I 740407/ 00203. (4 July 20 I8).

Corresponding Author

\section{Gwen Reddy}

Email: reddygwen@gmail.com 